

\title{
Regioselective chlorination of phenols in the presence of tetrahydrothiopyran derivatives
}

\author{
Keith Smith ${ }^{a}$, Des Williams ${ }^{\mathrm{b}}$ and Gamal A. El-Hiti ${ }^{\text {C }}$ \\ a School of Chemistry, Cardiff University, Cardiff, UK; ${ }^{b}$ Department of Chemistry, University of Wales Swansea,

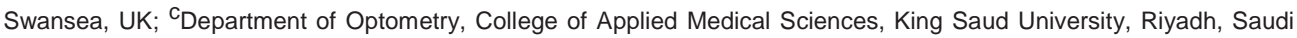 \\ Arabia
}

\begin{abstract}
Four six-membered cyclic sulfides, namely tetrahydrothiopyran, 3methyltetrahydrothiopyran, 4-methyltetrahydrothiopyran and 4,4dimethyltetrahyrdrothiopyran have been used as moderators in chlorination reactions of various phenols with sulfuryl chloride in the presence of aluminum or ferric chloride. On chlorination of phenol, ortho-cresol and meta-cresol the para/ortho chlorination ratios and yields of the para-chloro isomers are higher than when no cyclic sulfide is used for all of the cyclic sulfides, but chlorination of metaxylenol is less consistent, with some cyclic sulfides producing higher $p / o$ ratios and others producing lower ratios than reactions having no sulfide present.
\end{abstract}<smiles>[R]c1ccc(O)cc1</smiles><smiles>[R]C1CSCCC1([R])[R]</smiles><smiles>[R]c1ccc(O)cc1</smiles><smiles>[R]c1ccc(O)c(Cl)c1</smiles>
minor

\section{KEYWORDS}

Chlorination; cyclic sulfides; para/ortho ratio; phenols; regioselectivity

\section{Introduction}

Several chlorinated phenols are employed as or used in the production of herbicides, pesticides, disinfectants, dyes, and pharmaceuticals [1,2]. For example, 2,4-dichlorophenol is an important intermediate in the production of commercial herbicides, while 4-chloro-3,5dimethylphenol is used as a household antiseptic. Traditional phenol chlorination

CONTACT Gamal A. El-H@gelhiti@ksu.edu.sa epartment of Optometry, College of Applied Medical Sciences, King Saud University, PO Box 10219, Riyadh 11433, Saudi Arabia 
processes are not selective and produce significant waste [3]. Several chlorinating sys-tems have been reported for regioselective chlorination of phenols [4-16], including the use of Merrifield resin/sulfuryl chloride ( $\mathrm{SO}_{2} \mathrm{Cl}_{2}$ ) [5], aluminum-pillared mont-morillonite clay or L type zeolites/SO $2 \mathrm{Cl}_{2}$ [6], manganese(II) sulfate/hydrogen perox-ide/hydrogen chloride [7], ammonium chloride/1,3-dichloro-5,5-dimethylhydantoin [8], [bis(trifluoroacetoxy)iodo]benzene/aluminum chloride (AlCl3) [9], and Nagasawa's bisthiourea catalyst $/ N$-chlorosuccinimide [10]. However, such chlorinating systems lead to either limited para-selectivity, or to high ortho-selectivity, or cannot be applied on a large scale. Therefore, development of para-selective chlorination processes is still needed.

Several sulfides have been used as selective catalysts for the production of parachlorophenols [17-21]. For example, chlorination of phenol using $\mathrm{SO}_{2} \mathrm{Cl}_{2} /$ diphenyl

sulfide/ $\mathrm{AlCl} 3$ led to a para/ortho chlorophenol ratio of 10.5 [17]. Similarly, chlorination of $o$-cresol and $m$-cresol with such a system led to paralortho ratios of 19.0 and 7.5, respectively [17]. The para-selectivity was attributed to the bulk of the active intermediate complex $\mathrm{Ph}_{2} \mathrm{SCl}^{+} \mathrm{AlCl}_{4}^{-}$. Dialkyl sulfides (R-S-R') have also been used as selective moderators for production of para-chlorophenols. In this case, interesting variations were seen depending on the nature of the alkyl groups. In the absence of any Lewis acid, dibutyl and dipentyl sulfides showed greater para-selectivity for chlorination of phenol using sulfuryl chloride than other symmetrical dialkyl sulfides with either shorter or longer alkyl groups, and the para-selectivity was further enhanced in the presence of Lewis acids, especially

$\mathrm{AlCl}_{3}$ [18]. Also, with $m$-cresol as substrate, it was shown that the para-selectivity dropped as the level of steric hindrance of the alkyl group of alkyl $n$-butyl sulfides was increased from $n$-butyl to tert-butyl [18]. Clearly, these results are not consistent with the simple notion that the selectivity depends on the bulk of the complex $\mathrm{RR}^{\prime} \mathrm{SCl}^{+} \mathrm{AlCl}_{4}{ }^{-}$.

High paralortho ratios have also been achieved in chlorination of phenols in the presence of dithiaalkanes [R-S- $\left.\left(\mathrm{CH}_{2}\right) \mathrm{n}-\mathrm{S}-\mathrm{R}\right]$. In chlorination of $m$-cresol, compounds with longer spacer groups and with $\mathrm{R}$ groups around butyl in length provided the highest ratios (paralortho ratio of 20.7 for $n=12$ and $\mathrm{R}$ group $n$-butyl in the presence of $\mathrm{AlCl} 3$ ) [19]. A more extensive study revealed that $1, \omega$-bis(methylthio)alkanes with longer spacer groups ( $\omega$ $=6$ or 9) showed greatest para-selectivity in chlorination of $m$-cresol (paralortho ratio $=$ 18.0) and $m$-xylenol (para/ortho ratio $=19.6$ ), while 1, $\omega$-bis (methylthio)alkanes with shorter spacer groups $(\omega=2$ or 3 ) showed greater para-selectivity in chlorination of phenol (paralortho ratio $=11.4$ ) and $o$-cresol (paralortho ratio $=20.0)$ [20]. DFT calculations suggested that dithiaalkanes with shorter and longer spacer groups adopt different intermediate structures, with short spacer intermediates involving a $\mathrm{S}-\mathrm{Cl}^{+}-\mathrm{S}$ arrangement of heteroatoms, while longer spacer intermediates involve a $\mathrm{S}-\mathrm{S}^{+}-\mathrm{Cl}$ arrangement. However, use of disulfides as the moderators did not always follow the same pattern. For example, 1,2-dithiocane (hexamethylene disulfide) showed a higher para-selectivity (para/ortho ratio $=20.6$ ) than 1,2-dithiolane (trimethylene disulfide) in chlorination of $o$-cresol, while 1,2-dithiolane was the more selective in para-chlorination of $m$-xylenol (para/ortho ratio $=19.1$ ) [21]. On the other hand, para-selectivity in chlorination of both $o$-cresol and $m$-xylenol was higher with poly(trimethylene disulfide) than with poly(hexamethylene disulfide) [21]. Therefore, the factors influencing the levels of selectivity provided by different sulfur compounds as moderators are still unclear.

As part of our continuing contribution to the field of regioselective aromatic substitution reactions [22-39], in the current work we report the chlorination of a number 
of commercially important phenols using $\mathrm{SO}_{2} \mathrm{Cl}_{2}$ in presence of various tetrahydrothiopyran derivatives and a Lewis acid. The four tetrahydrothiopyrans chosen for the study were the parent tetrahydrothiopyran (1), 3-methyltetrahydrothiopyran (2), 4methyltetrahydrothiopyran (3) and 4,4-dimethyltetrahydrothiopyran (4). Since earlier work had indicated that $\alpha$-branching in the alkyl group of alkyl $n$-butyl sulfides caused significant diminution of the para-selectivity when used as the moderator in phenol chlo-rination reactions [18], 2-methyltetrahydrothiopyran was not included in the study. Com-pounds 2 and $\mathbf{3}$ offer alternative configurational/conformational arrangements between the active chlorine and the distal methyl group in the presumed chlorosulfonium inter-mediates, whereas compounds $\mathbf{1}$ and $\mathbf{4}$, which will have different steric interactions at a distance from the active chlorine in the intermediate, would not show configurational differences. It was hoped, therefore, that some meaningful insight might be gained into the subtle effects that influence the selectivity induced by sulfurcontaining activators in phenol chlorination reactions.

\section{Results and discussion}

The four tetrahydrothiopyrans 1-4 were synthesized by reactions of the appropriately sub-stituted 1,5-dibromopentanes with sodium sulfide nonahydrate at $170^{\circ} \mathrm{C}$ for $7 \mathrm{~h}$ (Scheme 1). The crude products obtained were purified by Kugelrohr distillation to give the pure cyclic sulfides $\mathbf{1 - 4}$ in $58-80 \%$ yield (Table 1) as colorless oils.

First, we attempted chlorination of phenol $(5, \mathrm{R}=\mathrm{H} ; 50 \mathrm{mmol})$ using freshly dis-tilled $\mathrm{SO}_{2} \mathrm{Cl}_{2}(55 \mathrm{mmol})$ in the presence of $\mathbf{1 - 4}(0.28 \mathrm{mmol})$ and $\mathrm{AlCl} 3(50 \mathrm{mg})$ at room temperature (RT; Scheme 2). Also, the reaction was attempted in the absence of cyclic sulfides both with and without $\mathrm{AlCl}_{3}$ to provide a baseline. The results are presented in Table 2. Clearly, the presence of any one of the cyclic sulfides 1-4 led to production of 4-chlorophenol $(6, \mathrm{R}=\mathrm{H})$ in a better yield (83.2-89.0\%) and with higher para-selectivity

(para/ortho ratio $=12.7-18.2)$ than when no catalyst was used (yield 63.7-70.1\% and<smiles>[R]C(CBr)C([R])([R])CCBr</smiles><smiles>[R]C1CSCCC1([R])[R]</smiles>

Scheme 1. Synthesis of tetrahydrothiopyrans 1-4.

Table 1. Yields of tetrahydrothiopyrans 1-4 according to Scheme 1.

\begin{tabular}{lcccc}
\hline Sulfide & $\mathrm{R}^{1}$ & $\mathrm{R}^{2}$ & $\mathrm{R}^{3}$ & Yield (\%) \\
\hline $\mathbf{1}$ & $\mathrm{H}$ & $\mathrm{H}$ & $\mathrm{H}$ & 80 \\
$\mathbf{2}$ & $\mathrm{Me}$ & $\mathrm{H}$ & $\mathrm{H}$ & 75 \\
$\mathbf{3}$ & $\mathrm{H}$ & $\mathrm{Me}$ & $\mathrm{H}$ & 79 \\
$\mathbf{4}$ & $\mathrm{H}$ & $\mathrm{Me}$ & $\mathrm{Me}$ & 58 \\
\hline
\end{tabular}




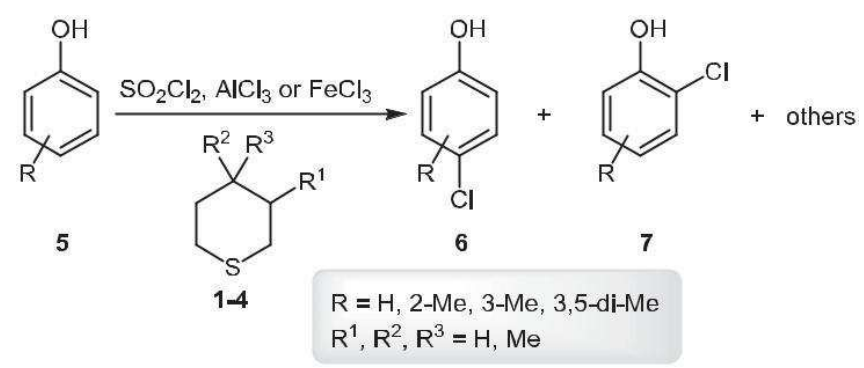

Scheme 2. Chlorination of phenols in the presence of cyclic sulfides 1-4 and $\mathrm{AlCl}_{3}$ or $\mathrm{FeCl} 3$.

Table 2. Chlorination of phenol $(5, \mathrm{R}=\mathrm{H})$ according to Scheme 2 . $^{\mathrm{a}}$

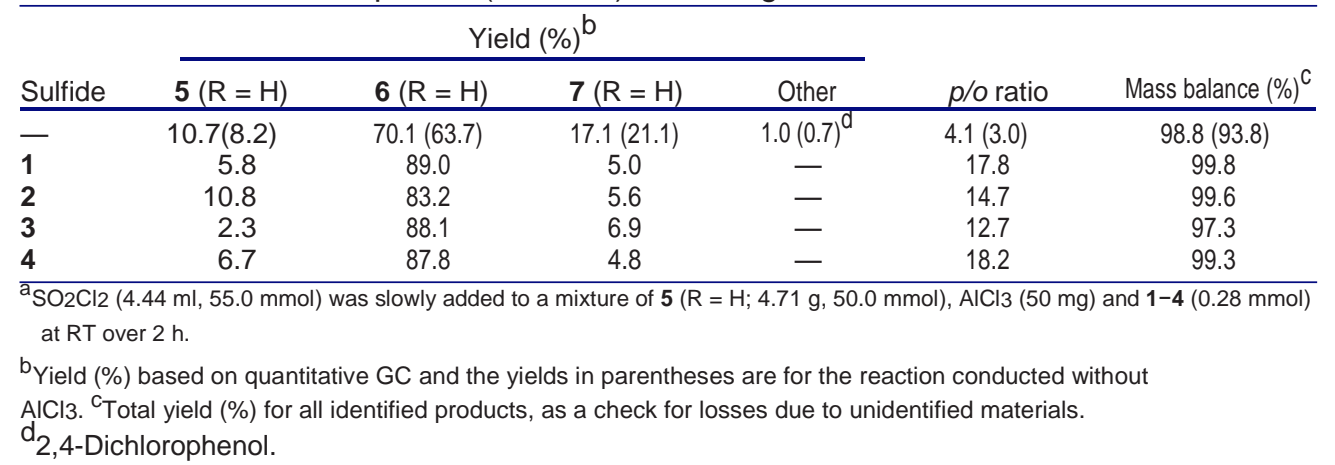

paralortho ratio $=3.0-4.1$ ). The unsubstituted tetrahydrothiopyran (1) led to the highest yield $(89.0 \%)$ of 4-chlorophenol, while 4,4-dimethyltetrahyrdrothiopyran 4 provided the highest paralortho ratio (18.2), but differences between the various moderators were not great and it is difficult to draw any general conclusions from such small differences, especially since significantly different quantities $(2.3-10.8 \%)$ of unreacted phenol (5; R $=\mathrm{H}$ ) were present in the different reaction mixtures.

Next, we investigated the chlorination of $o$-cresol $(5, \mathrm{R}=2-\mathrm{Me} ; 50 \mathrm{mmol})$ under the same conditions that were used for phenol, in the absence and presence of cyclic sulfides (Scheme 2). The results obtained are recorded in Table 3. The yield of 4-chloro2-methylphenol $(6, \mathrm{R}=2-\mathrm{Me})$ was only $75.1 \%$ when the reaction was carried out in the presence of $\mathrm{AlCl} 3$ without any of the cyclic sulfides 1-4. In the presence of catalysts

Table 3. Chlorination of 0 -cresol $(5, \mathrm{R}=2-\mathrm{Me})$ according to Scheme $2 .^{\mathrm{a}}$

\begin{tabular}{|c|c|c|c|c|c|c|}
\hline \multirow[b]{2}{*}{ Sulfide } & \multicolumn{3}{|c|}{ Yield $(\%)^{b}$} & \multirow[b]{2}{*}{ p/o ratio } & \multirow[b]{2}{*}{ Mass } & \multirow[b]{2}{*}{ balance $(\%)^{\mathrm{C}}$} \\
\hline & $5(\mathrm{R}=2-\mathrm{Me})$ & $6(\mathrm{R}=2-\mathrm{Me})$ & $7(\mathrm{R}=2-\mathrm{Me})$ & & & \\
\hline - & $9.6(2.0)$ & 75.1 (78.2) & $11.9(15.4)$ & $7.8(5.1)$ & & $99.0(99.8)$ \\
\hline 1 & - & 96.4 & 2.1 & 45.7 & & 98.5 \\
\hline 2 & 4.6 & 93.6 & 2.3 & 40.0 & & 100.5 \\
\hline 3 & - & 96.6 & 2.4 & 40.4 & & 99.0 \\
\hline 4 & 4.0 & 90.0 & 2.7 & 33.2 & & 96.7 \\
\hline
\end{tabular}


1-4, the yield of $6(\mathrm{R}=2-\mathrm{Me})$ was very high (90.0-96.6\%) and the paralortho ratio was improved from 7.8, when no sulfide was used, to 33.2-45.7. Such results highlight the importance of the sulfur atom within the cyclic sulfides for the para-selectivity of the chlo-rination reaction. Tetrahydrothiopyran (1) was the most para-selective catalyst and led to the highest paralortho ratio (45.7) and yield of $\mathbf{6}$ (96.4\%). Again, however, the differences between the different cyclic sulfides were not great.

Chlorination of $m$-cresol $(5, \mathrm{R}=3-\mathrm{Me} ; 50 \mathrm{mmol})$ with $\mathrm{SO}_{2} \mathrm{Cl}_{2}(55 \mathrm{mmol})$ and $\mathrm{AlCl}_{3}$ gave the results recorded in Table 4. The yields of 4-chloro-3-methylphenol $(6, \mathrm{R}=3$-Me) obtained when cyclic sulfides were present were broadly comparable to that obtained when no sulfide was used (87.2\%), but the paralortho ratios were significantly increased from 9.2 in the absence of sulfide to 15.6-19.2 in the presence of 1-4 because the reaction mixtures contained significantly lower quantities of the ortho-isomer $7(\mathrm{R}=3-\mathrm{Me})$ and significantly larger quantities of unreacted $m$-cresol (4.5-15.4\%). 4,4-Dimethyltetrahydrothiopyran (4) provided the highest paralortho ratio (19.2) and yield of $6(\mathrm{R}=3$-Me; 90.4\%), although the differences with the different sulfides were again not large.

Finally, chlorination of $m$-xylenol $(5, \mathrm{R}=2,3$-di-Me; $50 \mathrm{mmol})$ was attempted under conditions similar to those used for the chlorination of other phenols. However, since $m$ xylenol is solid at RT and unlike the other phenols cannot be melted and then retain its liquid form in the presence of the other reaction components, a solvent (perchloroethylene) had to be used. Also, $\mathrm{AlCl} 3$ was replaced by ferric chloride $(\mathrm{FeCl} 3)$ as the activator, since in order to be consistent with the requirements for use of the prod-uct $6(\mathrm{R}=2,3-\mathrm{di}-\mathrm{Me})$ as a commercial household antiseptic the product would have to contain a very low proportion of Al. The results (Table 5) are in contrast with those obtained for other phenols. Cyclic sulfides 1 and $\mathbf{2}$ provided higher proportions of 4chloro-3,5-dimethylphenol (paralortho ratio $=9.0-13.5$ compared with a paralortho ratio of 6.9-7.0 when no sulfide was used), but sulfides $\mathbf{3}$ and $\mathbf{4}$ provided very low propor-tions of 4-chloro-3,5-dimethylphenol (paralortho ratio $=1.9-3.7$ ). Such results clearly indicate that steric hindrance within the moderator is not the only driving force for the regioselectivity of these reactions. Clearly, the sulfur atom within the cyclic sulfides has a significant effect on the regioselectivity of the chlorination reaction of phenols using $\mathrm{SO}_{2} \mathrm{Cl}_{2}$, but the wider structure of the sulfur-containing molecule is also important.

Table 4. Chlorination of $m$-cresol $(5, \mathrm{R}=3-\mathrm{Me})$ according to Scheme 2. ${ }^{\mathrm{a}}$

\begin{tabular}{|c|c|c|c|c|c|}
\hline \multirow[b]{2}{*}{ Sulfide } & \multicolumn{3}{|c|}{ Yield $(\%)^{b}$} & \multirow[b]{2}{*}{$p / o$ ratio } & \multirow[b]{2}{*}{ Mass balance $(\%)^{d}$} \\
\hline & $5(\mathrm{R}=3-\mathrm{Me})$ & $6(\mathrm{R}=3-\mathrm{Me})^{\mathrm{C}}$ & $7(\mathrm{R}=3-\mathrm{Me})$ & & \\
\hline- & $2.5(3.2)$ & $87.2(86.0)$ & $9.5(10.0)$ & $9.2(8.6)$ & $99.2(99.2)$ \\
\hline 1 & 4.3 & 89.6 & 5.7 & 15.6 & 99.6 \\
\hline 2 & 7.9 & 82.9 & 5.2 & 15.9 & 96.0 \\
\hline 3 & 15.4 & 78.4 & 4.5 & 17.3 & 98.3 \\
\hline 4 & 4.7 & 90.4 & 4.7 & 19.2 & 99.8 \\
\hline \multirow{2}{*}{\multicolumn{6}{|c|}{$\begin{array}{l}\text { a } \mathrm{SO} 2 \mathrm{Cl} 2(4.44 \mathrm{ml}, 55.0 \mathrm{mmol}) \text { was slowly added to a mixture of } 5(\mathrm{R}=3-\mathrm{Me} ; 5.41 \mathrm{~g}, 50.0 \mathrm{mmol}), \mathrm{AlCl}_{3}(0.25 \mathrm{~g}) \text { and } \mathbf{1 - 4}(0.40 \\
\mathrm{mmol}) \text { at RT over } 2 \mathrm{~h} \text {. } \\
\text { b See footnote b to Table } 1 .\end{array}$}} \\
\hline & & & & & \\
\hline \multicolumn{6}{|c|}{$\begin{array}{l}\text { c Sum total of mixture of 2-chloro-3-methylphenol and 6-chloro-3-methylphenol (the two ortho-chlorinated products), which were } \\
\text { not fully resolved by the GC system used. } \\
\text { d See footnote c to Table } 1 .\end{array}$} \\
\hline
\end{tabular}


Table 5. Chlorination of $m$-xylenol (5, R =3,5-di-Me) according to Scheme 2. ${ }^{\mathrm{a}}$

\begin{tabular}{|c|c|c|c|c|c|c|}
\hline \multirow[b]{2}{*}{ Sulfide } & \multicolumn{4}{|c|}{ Yield $(\%)^{b}$} & \multirow[b]{2}{*}{ p/o ratio } & \multirow[b]{2}{*}{ Mass balance $(\%)^{C}$} \\
\hline & $5(\mathrm{R}=3,5-\mathrm{di}-\mathrm{Me})$ & $6(\mathrm{R}=3,5-\mathrm{di}-\mathrm{Me})$ & $7(\mathrm{R}=3,5-\mathrm{di}-\mathrm{Me})$ & Other $^{d}$ & & \\
\hline - & $15.4(13.4)$ & $71.1(68.6)$ & $10.3(9.8)$ & $-(-)$ & $6.9(7.0)$ & $96.8(91.8)$ \\
\hline 1 & 2.8 & 89.1 & 6.6 & 0.7 & 13.5 & 99.2 \\
\hline 2 & 7.1 & 78.1 & 8.7 & 2.9 & 9.0 & 96.8 \\
\hline 3 & 15.4 & 53.8 & 27.7 & - & 1.9 & 96.9 \\
\hline 4 & 5.8 & 73.6 & 19.7 & - & 3.7 & 99.1 \\
\hline $\begin{array}{l}\mathrm{a}_{\mathrm{SO}_{2} \mathrm{Cl}} 2 \\
(0.05 \mathrm{~m} \\
\text { bYield }(\% \\
\mathrm{FeCl}_{3}{ }^{\mathrm{c}} \mathrm{s} \\
\mathrm{d}_{2,4-\mathrm{Dic}}\end{array}$ & $\begin{array}{l}4 \mathrm{ml}, 55.0 \mathrm{mmol} \text { ) was } \\
\text { () in tetrachloroethylen } \\
\text { ased on quantitative } \\
\text { footnote c to Table } \\
\text { bro-3,5-dimethylph }\end{array}$ & $\begin{array}{l}\text { slowly added to a mixtur } \\
\text { (TCE; } 25 \mathrm{ml} \text { ) at RT ov } \\
\text { GC and the yields in } p \\
\text { enol. }\end{array}$ & $\begin{array}{l}\text { of } 6(\mathrm{R}=3,5-\mathrm{di}-\mathrm{Me} ; 6 \\
\mathrm{r} 2 \mathrm{~h} \text {. } \\
\text { rentheses are for the }\end{array}$ & $\begin{array}{l}1 \mathrm{~g}, 50.0 \\
\text { eaction } \mathrm{c}\end{array}$ & $\begin{array}{l}\mathrm{mol} \text { ), } \mathrm{FeCl} 3(2 \\
\text { nducted with }\end{array}$ & $\begin{array}{l}25 \mathrm{mg} \text { ) and 1-4 } \\
\text { out }\end{array}$ \\
\hline
\end{tabular}

\section{Conclusion}

Four cyclic sulfides have been synthesized and used as potential moderators for chlorination of phenols with freshly distilled sulfuryl chloride and a Lewis acid promoter. For three of the phenols tested (phenol, ortho-cresol and meta-cresol) the para-isomers were produced more regioselectively and usually in (often substantially) higher yields than in corresponding reactions carried out in the absence of cyclic sulfide, regardless of the cyclic sulfide used. However, the situation with meta-xylenol was different, with two of the sulfides (1 and 2) giving an increased proportion of para-chlorinated product and two (3 and 4) giving a higher proportion of ortho-chlorinated product than in the absence of any sulfide. Since the methyl group(s) in these latter sulfides are further away from the active sulfur atom than the methyl group in $\mathbf{2}$ it does not appear that the only driving force for the selectivity changes is steric hindrance, providing further support for the idea that the effects of sulfur compounds on such chlorination reactions are more subtle.

\section{Experimental Section}

\subsection{General}

Chemicals purchased from Aldrich and Lancaster Chemicals were mostly used as purchased. Sulfuryl chloride was distilled under an inert atmosphere at atmospheric pressure. Gas chromatography (GC) was carried out using a Shimadzu GC-2014 instrument with a capillary ZB Carbowax column (30 m, $0.32 \mathrm{~mm}$ ID) and temperature programed $\left(40^{\circ} \mathrm{C}\right.$ for 3 min, then ramped at $10^{\circ} \mathrm{C} / \mathrm{min}$ to $220^{\circ} \mathrm{C}$, then held for $8 \mathrm{~min}$ ) with an injection tempera-ture of $300^{\circ} \mathrm{C}$ and a detection temperature $250^{\circ} \mathrm{C}$. To allow quantification, tetradecane was added as a standard. Commercial samples of expected phenol chlorination products were used to determine retention times and response factors for each product. ${ }^{1} \mathrm{H}(400 \mathrm{MHz})$ and ${ }^{13} \mathrm{C}$ NMR (100 MHz) spectra were recorded on a Bruker AV400 spectrometer. Chemi-cal shifts $\delta$ are reported in parts per million (ppm) relative to TMS and coupling constants $J$ in $\mathrm{Hz}$ have been rounded to the nearest integer. DEPT spectra were used to determine ${ }^{13} \mathrm{C}$ multiplicities. Assignments of NMR signals are based on expected chemical shifts, integration values and coupling patterns and have not been rigorously confirmed. Low-resolution mass spectra were recorded on a Quattro II spectrometer at $70 \mathrm{eV}$. High-resolution mass spectra data were obtained on a MAT900 instrument. 


\subsection{Typical procedure for the preparation of cyclic sulfides 1-4}

A mixture of the appropriately substituted 1,5-dibromopentane and sodium sulfide nonahydrate (for quantities, see individual compound sections) was heated at $170^{\circ} \mathrm{C}$ for $7 \mathrm{~h}$ in an oil bath. After cooling, water $(20 \mathrm{ml})$ and dichloromethane (DCM, $20 \mathrm{ml})$ were added. The phases were separated and the aqueous layer was re-extracted with DCM $(3 \times 20 \mathrm{ml})$. The combined organic phases were washed with $\mathrm{H}_{2} \mathrm{O}(30 \mathrm{ml})$ and dried over anhydrous $\mathrm{MgSO} 4$. Removal of the solvent under reduced pressure gave the crude product, which was purified by Kugelrohr distillation to give the pure cyclic sulfides 1-4.

\subsubsection{Tetrahydrothiopyran (1)}

Yield $1.60 \mathrm{~g}(80 \%)$ from 1,5-dibromopentane $(4.00 \mathrm{~g}, 17.4 \mathrm{mmol})$ and sodium sulfide non-ahydrate $(6.27 \mathrm{~g}, 26.1 \mathrm{mmol})$ as a colorless oil $\left(\mathrm{Bp} 50-55^{\circ} \mathrm{C}\right.$ at $15 \mathrm{mmHg}$; lit. $140-141^{\circ} \mathrm{C}$ at RT [40]). ${ }^{1} \mathrm{H}-\mathrm{NMR}\left(\mathrm{CDCl}_{3}\right) \delta(\mathrm{ppm}): 1.60$ (m, $\left.2 \mathrm{H}\right), 1.85(\mathrm{~m}, 4 \mathrm{H}), 2.65$ $(\mathrm{m}, 4 \mathrm{H}) ;{ }^{13} \mathrm{C}-\mathrm{NMR}(\mathrm{CDCl} 3) \delta$ (ppm): 26.8, 28.1, 29.4; ${\mathrm{MS}-\mathrm{EI}^{+}}^{+} \mathrm{m} / \mathrm{z}(\%) 102\left([\mathrm{M}]^{+}\right.$, 100), 87 (95), 67 (60), 46 (75), 39 (80).

\subsubsection{3-Methyltetrahydrothiopyran (2)}

Yield $1.44 \mathrm{~g} \mathrm{(75 \% )} \mathrm{from} \mathrm{1,5-dibromo-2-methylpentane} \mathrm{(4.01} \mathrm{g,} 16.4 \mathrm{mmol})$ and sodium sulfide nonahydrate $(7.88 \mathrm{~g}, 32.8 \mathrm{mmol})$ as a colorless oil $\left(\mathrm{Bp} 70^{\circ} \mathrm{C}\right.$ at $20 \mathrm{mmHg}$; lit. $158^{\circ} \mathrm{C}$ at RT [41]). ${ }^{1} \mathrm{H}-\mathrm{NMR}(\mathrm{CDCl} 3) \delta(\mathrm{ppm}): 0.89(\mathrm{~d}, J=7.5 \mathrm{~Hz}, 3 \mathrm{H}), 1.61-2.00$ (m, $5 \mathrm{H}), 2.22-2.53(\mathrm{~m}, 4 \mathrm{H}) ;{ }^{13} \mathrm{C}-\mathrm{NMR}(\mathrm{CDCl} 3) \delta$ (ppm): 23.1, 28.1, 28.8, 33.5, 35.2, 36.1; $\mathrm{MS} \mathrm{EI}^{+} \mathrm{m} / z(\%) 116\left(\left[\mathrm{M}^{+}\right]\right.$90), $101(100)$.

\subsubsection{4-Methyltetrahydrothiopyran (3)}

Yield $0.38 \mathrm{~g}(79 \%)$ from 1,5-dibromo-3-methylpentane (1.00 g, $4.1 \mathrm{mmol})$ and sodium sul-fide nonahydrate $(1.48 \mathrm{~g}, 6.1 \mathrm{mmol})$ as a colorless oil $\left(\mathrm{Bp} 50-55^{\circ} \mathrm{C}\right.$ at $20 \mathrm{mmHg}$; lit. $54^{\circ} \mathrm{C}$ at $\left.22 \mathrm{mmHg}[41]\right) .{ }^{1} \mathrm{H}-\mathrm{NMR}\left(\mathrm{CDCl}_{3}\right) \delta(\mathrm{ppm}): 0.85(\mathrm{~d}, J=6 \mathrm{~Hz}, 3 \mathrm{H}), 1.10$ -1.40 (m, $4 \mathrm{H}), 1.90(\mathrm{~m}, 1 \mathrm{H}), 2.45-2.55(\mathrm{~m}, 4 \mathrm{H}) .{ }^{13} \mathrm{C}-\mathrm{NMR}(\mathrm{CDCl} 3) \delta$ 23.4, 29.2, 32.6, 36.3; MS EI $m / z(\%) 116\left(\left[\mathrm{M}^{+}, 100\right), 101(95), 67\right.$ (90), 41 (85).

\subsubsection{4,4-Dimethyltetrahyrdrothiopyran (4)}

Yield $0.26 \mathrm{~g}(58 \%)$ from 1,5-dibromo-3,3-dimethylpentane $(1.00 \mathrm{~g}, 3.87 \mathrm{mmol})$ and sodium sulfide nonahydrate $(1.40 \mathrm{~g}, 5.81 \mathrm{mmol})$ as a colorless oil $\left(\mathrm{Bp} 60-65^{\circ} \mathrm{C}\right.$ at 15 $\mathrm{mmHg}$; lit. $57-58^{\circ} \mathrm{C}$ at $\left.15 \mathrm{mmHg}[42]\right) .{ }^{1} \mathrm{H}-\mathrm{NMR}(\mathrm{CDCl} 3) \delta(\mathrm{ppm}): 0.75(\mathrm{~s}, 6 \mathrm{H})$, $1.40-1.60(\mathrm{~m}, 4 \mathrm{H})$ 2.50-2.60 (m, $4 \mathrm{H}) ;{ }^{13} \mathrm{C}-\mathrm{NMR}\left(\mathrm{CDCl}_{3}\right) \delta(\mathrm{ppm}): 24.8,26.9,28.8$, 40.2; $\mathrm{MS} \mathrm{EI}^{+} \mathrm{m} / z(\%) 130\left([\mathrm{M}]^{+}, 90\right), 115(95), 69(70), 41(80)$.

\subsection{Chlorination of phenol, o-cresol and $m$-cresol}

Phenol (melted), $o$-cresol (melted) or $m$-cresol (50.0 mmol), $\mathrm{AlCl}_{3}(25-50 \mathrm{mg}$ ) and the appropriate cyclic sulfide 1-4 (0.28-0.40 mmol; see Tables $1-4$ for details) were placed in a dried round bottomed flask $(50 \mathrm{ml})$. The mixture was stirred as sulfuryl chloride $(4.44 \mathrm{ml}$, $55.0 \mathrm{mmol}$ ) was added slowly over $2 \mathrm{~h}$ via a pressure equalizing dropping funnel and for $2 \mathrm{~h}$ further. The reaction was quenched with water $(20 \mathrm{ml})$ and the organic components were then extracted with diethyl ether $(3 \times 30 \mathrm{ml})$. The combined ether layers were dried over 
$\mathrm{MgSO}$, which was removed by filtration. The solvent was removed under reduced pressure to give the crude product, which was weighed. Quantitative GC analysis was conducted on a weighed aliquot of the product with a known quantity of tetradecane.

\subsection{Chlorination of m-xylenol}

m-Xylenol (6.11 g, $50.0 \mathrm{mmol}), \mathrm{FeCl}_{3}(25 \mathrm{mg})$, tetrachloroethylene $(25 \mathrm{ml})$ and the appro-priate cyclic sulfide 1-4 $(0.05 \mathrm{mmol})$ were placed in a dried round bottom flask $(50 \mathrm{ml})$. The mixture was stirred as freshly distilled sulfuryl chloride $(4.44 \mathrm{ml}, 55.0$ mmol) was added slowly over $2 \mathrm{~h}$ via a pressure equalizing dropping funnel and then for another $2 \mathrm{~h}$. The work-up and analysis of the products by GC were as previously described for other phenols.

\section{Acknowledgments}

The authors extend their appreciation to Cardiff and Swansea Universities for their support of this research. G. A. El-Hiti thanks the College of Applied Medical Sciences Research Centre and the Deanship of Scientific Research at King Saud University for funding his research.

\section{Disclosure statement}

No potential conflict of interest was reported by the authors.

\section{Funding}

The authors extend their appreciation to Cardiff and Swansea Universities for their support of this research.

\section{ORCID}

Gamal A. El-Hiti (]) http://orcid.org/0000-0001-6675-3126

\section{References}

[1] Ullmann's Encyclopedia of Industrial Chemistry. 6th ed. Wiley-VCH: Weinheim; 1998.

[2] Grant MH. Kirk-Othmer encyclopaedia of chemical technology. 4th ed. New York (NY): Wiley Interscience; 1992.

[3] Gibson GP. CLXXXV. - the monochloro-derivatives of $m$-cresol. J Chem Soc. 1926;129: $1424-1428$.

[4] Sah PPT, Anderson HH. The preparation and properties of three isomeric $n$-hexyl cresols and their chlorinated derivatives. J Am Chem Soc. 1941;63:3164-3167.

[5] Bugnet EA, Brough AR, Greatrex R, et al. On the para-selective chlorination of orthocresol. Tetrahedron. 2002;58:8059-8065.

[6] Gnaim JM, Sheldon RA. Shape-selective para-chlorination of phenol using sulfuryl chloride with the aid of microporous catalysts. Tetrahedron Lett. 2004;45:9397-9399.

[7] Xin H, Yang S, An B, et al. Selective water-based oxychlorination of phenol with hydrogen peroxide catalyzed by manganous sulfate. RSC Adv. 2017;7:13467-13472.

[8] Xiong X, Yeung Y-Y. Ammonium salt-catalyzed highly practical ortho-selective monohalogenation and phenylselenation of phenols: scope and applications. ACS Catal. 2018;8: 4033-4043. 
[9] Nahide PD, Ramadoss V, Juárez-Ornelas KA, et al. In situ formed I(III)-based reagent for the electrophilic ortho-chlorination of phenols and phenol ethers: the use of PIFA- $\mathrm{AlCl}_{3}$ system. Eur J Org Chem. 2018;2018:485-493.

[10] Maddox SM, Dinh AN, Armenta F, et al. The catalyst-controlled regiodivergent chlorination of phenols. Org Lett. 2016;18:5476-5479.

[11] Bovonsombat P, Ali R, Khan C, et al. Facile p-toluenesulfonic acid-promoted para-selective monobromination and chlorination of phenol and analogues. Tetrahedron. 2010;66:69286935.

[12] Priya V, Mathiyalagan N. Chlorination of phenol and p-nitrophenol by $\mathrm{N}$ chloronicotinamide in aqueous acetic acid medium, kinetic and mechanistic study. Asian J Chem. 2010;22: 5218-5222.

[13] Singh PP, Thatikonda T, Kumar KAA, et al. Cu-Mn spinel oxide catalyzed regioselective halogenation of phenols and $N$-heteroarenes. J Org Chem. 2012;77:5823-5828.

[14] Sun X, Sun Y, Zhang C, et al. Room-temperature Pd-catalyzed C-H chlorination by weak coor-dination: one-pot synthesis of 2-chlorophenols with excellent regioselectivity. Chem Commun. 2014;50:1262-1264.

[15] Geetha S, Namrata P. Effect of acetic acid on chlorination of some phenols by ChloramineT: a kinetic approach. Res J Chem Sci. 2014;4:86-89.

[16] Xiong Y, Duan H, Meng X, et al. Highly selective synthesis of chlorophenols under microwave irradiation. J Chem. 2016;2016:1-5.

[17] Watson WD. Regioselective para-chlorination of activated aromatic compounds. J Org Chem. 1985;50:2145-2148.

[18] Smith K, Tzimas M, Brown CM, et al. Dialkyl sulf ides as selective catalysts for the chlorination of phenols. Sulfur Lett. 1999;22:89-101.

[19] Smith K, Tzimas M, Brown CM, et al. Dithiaalkanes and modif ied Merrif ield resins as selective catalysts for the chlorination of phenols. Sulfur Lett. 1999;22:103-123.

[20] Smith K, Al-Zuhairi AJ, Elliott MC, et al. Regioselective synthesis of important chlorophenols in the presence of methylthioalkanes with remote SMe, OMe or $\mathrm{OH}$ substituents. J Sulfur Chem. 2018;39:607-621.

[21] Smith K, Al-Zuhairi AJ, El-Hiti GA, et al. Comparison of cyclic and polymeric disul-fides as catalysts for the regioselective chlorination of phenols. J Sulfur Chem. 2015;36: 74-85.

[22] Smith K, El-Hiti GA. Catalytic, green and regioselective Friedel-Crafts acylation of simple aromatics and heterocycles over zeolites. Curr Org Chem. 2015;19:585-598.

[23] Smith K, Alotaibi MH, El-Hiti GA. Highly regioselective dinitration of toluene over zeolite H $\beta$. J Catal. 2013;297:244-247.

[24] Smith K, Al-Khalaf AKH, El-Hiti GA, et al. Highly regioselective di-tert-amylation of naph-thalene over reusable HM zeolite catalyst. Green Chem. 2012;14:1103-1110.

[25] Smith K, El-Hiti GA. Use of zeolites for green and para-selective electrophilic aromatic substitution reactions. Green Chem. 2011;13:1579-1608.

[26] Smith K, Barratt ML. 5-Substitution of 3-methylthiophene via highly selective lithiation. J Org Chem. 2007;72:1031-1034.

[27] Smith K, Ewart GM, El-Hiti GA, et al. Study of regioselective methanesulfonylation of simple aromatics with methanesulfonic anhydride in the presence of zeolite catalysts. Org Biomol Chem. 2004;2:3150-3154.

[28] Smith K, El-Hiti GA, Butters M. Acetylation of aromatic ethers using acetic anhydride over solid acid catalysts in a solvent-free system. Scope of the reaction for substituted ethers. Org Biomol Chem. 2003;1:1560-1564.

[29] Smith K, Roberts SD, El-Hiti GA. Study of regioselective dialkylation of naphthalene in the presence of reusable zeolite catalysts. Org Biomol Chem. 2003;1:1552-1559.

[30] Smith K, El-Hiti GA, Bahzad D, et al. Highly ef $\mathrm{f}$ icient and selective electrophilic and free radical catalytic bromination reactions of simple aromatic compounds using bromine in the presence of reusable zeolites. J Chem Soc Perkin Trans. 2000;1:2745-2752. 
[31] Smith K, Butters M, Paget WE, et al. Highly selective monochlorination of aromatic compounds under mild conditions by tert-butyl hypochlorite in the presence of zeolites. Green Chem. 1999;1:83-90.

[32] Smith K, Zhenhua Z, Hodgson PKG. Synthesis of aromatic ketones by acylation of aryl ethers with carboxylic anhydrides in the presence of zeolite H- $\beta$ (H-BEA) in the absence of solvent. J Mol Catal A. 1998;134:121-128.

[33] Smith K, Musson A, DeBoos GA. A novel method for the nitration of simple aromatic compounds. J Org Chem. 1998;63:8448-8454.

[34] Smith K, Ewart GM, Randles KR. Regioselective methanesulfonylation of toluene catalysed by cation-exchanged zeolite beta. J Chem Soc Perkin Trans. 1997;1:1085-1086.

[35] DeLaude L, Laszlo P, Smith K. Heightened selectivity in aromatic substitutions by the use of solid supports and catalysts. Acc Chem Res. 1993;26:607-613.

[36] Smith K, James DM, Matthews I, et al. Selective para-bromination of phenols via a regenerable polymer-bound tetralkylammonium tribromide. J Chem Soc Perkin Trans. 1992;1:1877-1878.

[37] Smith K, Pritchard GJ. Carbonylation of doubly lithiated $N$-pivaloylanilines: a novel approach to dioxindoles via intramolecular trapping of aromatic acyllithiums. Angew Chem Int Ed. 1990;29:282-283.

[38] Smith K, Lindsay CM, Pritchard GJ. Directed lithiation of arenethiols. J Am Chem Soc. 1989;111:665-669.

[39] Smith K, Butters M, Nay B. Highly para-selective mono-chlorination of aromatic compounds under mild conditions by $t$-butyl hypochlorite in the presence of zeolites. Synthesis. 1985;1985:1157-1158.

[40] Bordwell FG, Hewett WA. Synthesis from thiolesters. II. Synthesis of cyclic sulf ides. J Org Chem. 1958;23:636-637.

[41] Whitehead EV, Dean RA, Fidler FA. The preparation and physical properties of sulfur compounds related to petroleum. II. Cyclic sulfides. J Am Chem Soc. 1951;73:3632-3635.

[42] Schmerling L, West JP. Condensation of saturated halides with unsaturated compounds. VIII. condensation of dihaloalkanes with ethylene and chloroethylenes. J Am Chem Soc. 1952;74:2885-2889. 